\title{
LA INFLUENCIA DE LAS CLASIFICACIONES DE DERECHOS HUMANOS EN LA EXIGIBILIDAD DE LOS DERECHOS ECONÓMICOS, SOCIALES Y CULTURALES
}

\author{
The Influence of Human Rights Classifications in the Enforcement \\ of Economic, Social and Cultural Rights
}

Carlos Salvador RODRÍGUEZ CAMARENA ${ }^{1^{*}}$

Sumario:

I. Introducción. II. Origen de las clasificaciones de derechos humanos. III. La influencia de las clasificaciones en la exigibilidad de los derechos económicos, sociales y culturales. IV. La dimensión "prestacional" de todos los derechos. V. Conclusión. VI. Fuentes de consulta.

Resumen: Este trabajo examina la influencia que las clasificaciones más conocidas de derechos humanos tienen sobre la exigibilidad de los derechos económicos, sociales y culturales. Las teorías que existen en torno a la dificultad para exigir esos derechos tienen su origen en diversas cuestiones, que van desde la falta de una conceptualización aprehensible y clara, pasando por las y a superadas aparentes contradicciones teóricas entre igualdad y libertad, hasta el diseño de mecanismos que permiten hacer efectivas las pretensiones. Es un hecho que los derechos sociales carecen todavía de eficacia. Dicha carencia ha llevado a los teóricos, sobre todo a los liberales, a cuestionar su fundamentalidad desde diversos ámbitos, atacando incluso las razones que les dan sustento. Desde el punto de vitas jurídico es necesaria la labor de caracterización pues, de ahí parte el trabajo por lograr mejores niveles de exigibilidad de los derechos. No obstante, cualquier aproximación casi siempre parte de algún tipo de clasificación de los derechos que, lejos de ayudar a fortalecer la exigibilidad la debilita e incluso la perjudica.

Palabras clave: exigibilidad, clasificación, derechos sociales.

Abstract: This paper examines how the accepted classifications on Human Rights influence the enforceability of the economic, social and cultural rights. Existing assertions about how difficult is to enforce those rights have their origin in various issues, like the lack of a graspable and clear concept, the apparent theoretical contradictions between equality and freedom, or the difficulty to design effective mechanisms to enforce the claims. It is a fact that social rights still lack effectiveness. This deficiency has led theorists, especially liberals, to question their fundamentality from various fields, which have led to attack even the reasons that give them sustenance. From a legal perspective it is necessary to characterize the social rights since that is the starting point to achieve better levels of understanding and enforcement. However, this approach almost always develops from a certain classification of rights that, far from helping to strengthen the social rights enforcement, rather weakens and even detriments them.

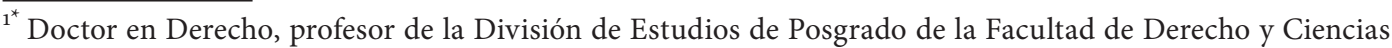
Sociales, Universidad Michoacana de San Nicolás de Hidalgo.
} 
Keywords: Enforcement, classification, social rights.

\section{INTRODUCCIÓN}

Existe la idea de que los derechos económicos, sociales y culturales no son fácilmente exigibles, derivada de algunas teorías en torno a su naturaleza que plantean diferencias entre esos derechos y los derechos civiles y políticos. Hay también un consenso más o menos generalizado de que una de las principales diferencias radica en que los derechos económicos, sociales y culturales imponen al Estado obligaciones de dar y hacer, en tanto que los derechos civiles y políticos sólo le generan obligaciones de no hacer. Una conclusión inevitable, es que los derechos civiles y políticos son exigibles ante los tribunales o ante organismos públicos de derechos humanos, en tanto que los derechos económicos, sociales y culturales deben seguir un camino azaroso, por decir lo menos, para alcanzar el mismo privilegio.

La posición dogmática que ve a los derechos sociales como derechos "sobre el papel", distinguiéndolos de los "derechos verdaderos" ${ }^{2}$ todavía mantiene fuerza y vigencia. Son derechos, afirman, no susceptibles de tutela jurisdiccional, porque muchas de las veces carecen de sujeto pasivo contra el cual articularlos; tampoco tienen un contenido obligacional definido o definible. Estos derechos, dicen, son conceptualmente defectuosos, por lo que los jueces se encuentran imposibilitados para atender los reclamos de los titulares del derecho.

Hay también algunas teorías que, sobre la base de sus rasgos distintivos, ${ }^{3}$ concluyen que estos derechos no pueden ser tutelados en sede judicial o, en su caso, lo son de manera deficiente. También argumentan que los jueces, debido a que su designación no es democrática, están imposibilitados para medir las consecuencias que tendrían sus sentencias en otras esferas de decisión, políticas y administrativas, que involucran cuestiones presupuestales.

En mi opinión, todas estas tesis y posiciones derivan de la manera en que la doctrina ha clasificado los derechos humanos, por lo que considero necesario abordar nuevamente esas clasificaciones, para atender primero, de una manera diferente, el análisis de su naturaleza y estructura y luego pensar formas que los hagan exigibles ante las instancias judiciales y frente a los organismos públicos de derechos humanos. En este breve trabajo únicamente disertaré sobre las consecuencias que los enfoques sobre la forma de clasificar los derechos humanos han producido en la exigibilidad de los derechos civiles y políticos y derechos económicos, sociales y culturales.

\section{ORIGEN DE LAS CLASIFICACIONES DE DERECHOS HUMANOS}

Los cien años que transcurrieron entre 1850 a 1950, a nivel mundial, se caracterizaron por un exceso de dominación y sufrimiento humano deliberadamente infligido por quienes detentaron el poder. El imperialismo y la colonización y la explotación extrema de la clase trabajadora fueron la marca de este periodo. En el caso de los trabjadores manuales, las luchas por un simple permiso de organización se enfrentaron a la represión física e ideológica. En los Estados Unidos fue especialmente cruel. Pocos americanos saben que el $1^{\circ}$ de mayo conme-

\footnotetext{
${ }^{2}$ GUASTINNI, Riccardo, Distinguiendo, Barcelona, GEDISA, 1999, p. 185. También aparece en Guastini, Ricardo, Estudios de teoría constitucional, México, Fontamara-UNAM, 2001, pp. 220 y ss., Disponible en Internet, http://biblio.juridicas.unam.mx/libros/libro.htm?l=22.

3 Por ejemplo, su contenido indeterminado, su carácter programático o su costo económico. 
mora algo que ocurrió, no en Moscú o en París, sino en Chicago en 1886. Pocos saben que el origen de la National Guard (Guardia Nacional) de los Estados Unidos de América tiene su origen en las luchas del trabajo.

Al inicio del siglo XX pareciera que el sufrimiento y la dominación se incrementaron linealmente: al imperialismo y al colonialismo le sobrevinieron el totalitarismo, el genocidio y dos guerras mundiales que no discriminaron ni distinguieron entre tipo de armamento o entre civiles y militares.

Al aproximarse la Primera Guerra Mundial, el poder político, la rivalidad comercial y el nacionalismo se fusionaron en una concepción darwiniana de política exterior que culminó en una carnicería humana. La Primera Guerra, no obstante, también condujo a una revaluación de la legitimación de los Estados desde la perspectiva de los derechos humanos. ${ }^{4} \mathrm{Ya}$ Niestzsche, con anterioridad, había presagiado la tendencia europea hacia la autodestrucción y auto-despertar. "Este hecho de que la voluntad de verdad cobre consciencia de sí hace perecer de ahora en adelante - no cabe ninguna duda - la moral: ese gran espectáculo en cien actos, que permanece reservado a los dos próximos siglos de Europa, el más terrible, el más problemático, y acaso también el más esperanzador de todos los espectáculos".5 De hecho, durante y después de la Guerra, emergieron dos esfuerzos, opuestos, para institucionalizar los derechos del hombre: el triunfo bolchevique en Rusia y el casi simultáneo establecimiento de la Sociedad de Naciones con su Organización Internacional del Trabajo.

El fallo en la implementación de un mecanismo de esas visiones, ya liberal, ya socialista, para asegurar los derechos humanos, se debió al surgimiento de perspectivas particularistas. Los líderes del nacionalismo y de la realpolitik explotaron las frustraciones populares de este periodo. La reiteración del poder del Estado en un intenso periodo de nacionalismo culminó en el totalitarismo ${ }^{6}$ y en una renovada tendencia hacia la guerra. Aunque las monarquías y las dictaduras siempre han existido, la novedad en esos momentos fue la democracia en los estados-nación. Los estados totalitarios clamaron actuar en nombre del pueblo — volk, proletariat-. El totalitarismo fue aún más allá de Hobbes, quien sólo propuso extraer la obediencia política de manera absoluta, pero dejando libres de la intromisión política otros campos de la actividad humana. Hobbes pretendía pacificar a la gente políticamente. El totalitarismo trató de movilizarlos sin dejar campo alguno libre de la penetración y dominación del estado-partido. Para los Nazis, por ejemplo, no había derecho hu

mano alguno que pudiera ser reclamado por los ciudadanos contra el Estado alemán. Es interesante hacer notar que, en tanto el Estado Nazi nunca utilizó el discurso de los derechos humanos, los soviéticos sí lo utilizaron. Una lectura cuidadosa de las Constituciones soviéticas de $1936^{7}$ y $1977^{8}$ indica que esos derechos estaban condicionados a la aceptación acrítica de la supremacía del Estado-Partido. Después de declarar el refuerzo del sistema de

4 ISHAY, Micheline R. The History of Human Rights. From Ancient Times to the Globalization Era, 2a Ed., Berkeley, University of California Press, 2008, p. 176.

5 NIETZSCHE, Friedrich. La genealogía de la moral. Final del \$27. Visible en http://www.pensament.com/ filoxarxa/filoxarxa/pdf/Nietzsche,\%2oFriedrich\%20-\%2oGenealogia\%2ode\%2ola\%20moral\%2o (completo). pdf.

6 TROTSKY está entre los primeros que hacen uso del término "totalitario", aunque achaca a los alemanes el cuño de este concepto. Vid. TROTSKY, Leon. La revolución traicionada, visible en http://www.marxismo. org/ ?q=node/157.

7 Constitución Soviética de 1936. Visible en: http://www.eroj.org/biblio/stalin/constiz6/consti36.htm\#XIII.

8 BECERRA RAMÍREZ, Manuel, El factor jurídico en la transformación de la Unión Soviética a la Comunidad de Estados Independientes. México, UNAM, 1992, pp. 169-216. Visible en: http://www.bibliojuridica. org/ libros/2/827/11.pdf. 
control por la gente, la Constitución declara que el Partido Comunista, núcleo de su sistema político, es la fuerza que lidera y guía a la sociedad soviética y a todas las organizaciones públicas y del Estado. ${ }^{9}$ En la práctica, los soviéticos llevaron el rol del partido tan lejos que eventualmente no se pudo distinguir al Estado del Partido. Quienes rehusaron mantenerse acríticos y quienes usaron el discurso de los derechos como reclamo, fueron tratados como subversivos y contrarrevolucionarios.

El siglo XX trajo no sólo totalitarismo sino genocidio a escala masiva. No que el genocidio no fuese conocido con anterioridad. Si concordamos que "genocidio" se refiere a la destrucción de una cultura y a la eliminación física de su gente, el genocidio siempre ha existido: la institución de la esclavitud es genocida, de la misma manera que lo fue el trato que los pueblos indígenas recibieron en todo el continente americano. Uno pudiera pensar que después de dos siglos de caminar por los senderos trazados por los documentos políticos fundantes de los derechos del hombre el mundo se volvería más civilizado, pero no ha sido así. Al mundo le importó muy poco que los turcos masacraran a los armenios (1915-1917), como le importó muy poco que los nazis exterminaran a judíos, gitanos, homosexuales y oponentes políticos en el mayor genocidio que ha existido en la historia. Se cita a Hitler respondiendo, “¿Quién recuerda a los armenios?”, cuando alguien de su Estado Mayor le cuestionó si el mundo permitiría a los Nazis exterminar a los judíos. Pero el genocidio no ha parado. Encontramos ejemplos más recientes en Vietnam, Ruanda, en el desmembramiento de Yugoslavia (Bosnia), en Líbano, en Irak, en Siria, etcétera. El "mundo" a veces responde, pero siempre de manera timorata. Y a veces hasta cómplice es (Guatemala). ${ }^{10}$

No obstante, las experiencias de la guerra del alguna manera cambiaron las mentes y el universo político. No cabe duda que el régimen nazi debió ser detenido militarmente: pero la guerra, en sí, querámoslo o no, siempre implica graves violaciones a los derechos humanos.

Como la combinación de la guerra mundial, el totalitarismo y el genocidio resultaron en un asalto sin precedentes contra los derechos humanos, después de la victoria se "tenía" que hacer algo de manera oficial. Se hicieron tres cosas. Primero, algunos líderes del régimen Nazi fueron juzgados en Nürenberg por un tribunal de jueces que los países victoriosos designaron. El cargo fue "crímenes contra la humanidad". Debido a que no existía ninguna ley internacional que pudiera utilizarse para el juicio, se asumió que la ofensa se cometió contra un código moral no escrito, que debía ser del conocimiento de cualquier ser humano "razonable". El apoyo se encontró en el concepto tradicional judeo-cristiano de Ley Natural, que supone que todos los seres humanos, excepto, quizá aquellos nacidos con deficiencias mentales, tienen la suficiente razón para comprender que ciertas cosas no son moralmente permitidas, incluso si una ley positiva las declara permisibles o si son ordenadas por un superior.

Segundo, se creó la Organización de las Naciones Unidas (ONU) con el objeto de fomentar unas relaciones internacionales más pacíficas y cooperativas. Y, tercero, las Naciones Unidas emitieron declaraciones oficiales sobre los derechos humanos, las primeras emitidas desde que vieron la luz los documentos franceses y americanos de finales del siglo XVIII. Pero esta vez las declaraciones se emitieron en nombre del "mundo", con la obligación de los gobiernos de acordar o disentir de ellos. Su intención fue la de presentar un consenso de

\footnotetext{
9 Para una discusión y análisis ver OEHLING RUIZ, H., La nueva Constitución Soviética de 7 de octubre de 1977. Visible en http://www.cepc.es/rap/Publicaciones/Revistas/3/REPNE_oo2_o61.pdf.

10 BELDEN FIELDS, A., Rethinking human rights for the new millennium, New York, Palgrave Macmillan, 2003, pp. 33-39.
} 
opinión internacional sobre derechos humanos detallados y proclamados en documentos escritos.

Y en este punto de la historia es donde comienzan los disensos y los problemas para ver los derechos humanos desde un punto de vista integral; se empiezan a ver "diferencias" entre tipos de derechos y se les empieza a clasificar. En los hechos, a pesar de que Franklin D. Roosevelt apoyó lo que se conoce como Second Bill of Rights, con el objeto de garantizar la seguridad de los habitantes de los Estados Unidos de América (EUA) y a pesar del decidido apoyo de Eleanor Roosevelt para esos derechos cuando representó a los EUA en la Comisión de Derechos Humanos de la ONU durante la administración Truman, la Guerra Fría cambió el ambiente político en el mundo y provocó un estancamiento en el avance de los derechos humanos. La desazón que provocó en algunos países occidentales la inclusión de los ahora denominados derechos económicos y sociales en la Carta de 1948, aunado a los desacuerdos con el Bloque Comunista, causó que, desde 1951, los negociadores "occidentales” consideraran que sería mejor proponer dos convenios (pactos) separando, por un lado, los derechos políticos y civiles, y los derechos económicos, sociales y culturales, por el otro.

La Declaración Universal de los Derechos Humanos de la Organización de la Naciones Unidas de 10 de diciembre de 1948, se refiere en general a derechos humanos, incluyendo civiles, políticos, económicos, sociales y culturales, construidos sobre el concepto de dignidad. Después de los desencuentros que la Guerra fría provocó, fue hasta 1966, con Maurice Cranston encabezando la posición de un buen número de países occidentales, incluyendo a los EUA, que finalmente se trató de dar un contenido inicial a los derechos humanos en dos documentos (convenios o pactos), separando a los derechos políticos y civiles, por un lado, y a los derechos económicos, sociales y culturales por otro. Muchos países no firmaron este último. En el caso de los EUA, el presidente James Carter lo firmó en 1977, pero desde entonces permanece "embotellado" en el Senado, esperando su ratificación; y desde la Administración Reagan y el advenimiento del neoliberalismo (económico), la tendencia en los EUA es limitar los derechos humanos a los civiles y políticos. Existe una hostilidad similar en los gobiernos conservadores británicos en su actitud hacia los convenios europeos sobre derechos humanos. ${ }^{11}$

La ex Unión Soviética y los países de Europa Oriental ya habían reconocido muchos de los derechos sociales y económicos en sus constituciones y en la práctica (aunque su actitud con respecto a los derechos políticos y civiles dejara mucho que desear). En los recién independizados países del tercer mundo de África y Asia, los Pactos generaron grandes expectativas. Después de tantos años de colonialismo se sintieron con derecho a recibir eso y más. ${ }^{12} \mathrm{De}$ esta manera, aunque de inicio parecía existir un consenso mundial sobre la existencia de los derechos humanos, no existió acuerdo sobre su contenido. El desacuerdo no fue sólo sobre la lista de derechos, o si podían ser sólo los civiles y políticos, o incluir también a los económicos, sociales y culturales, sino también sobre quiénes deberían ser sus titulares.

Desde el punto de vista de la doctrina, aunque se aceptó en general la existencia de los derechos humanos, se negó y aún se niega la existencia de alguna base, racional o no, para esos derechos. Así, los conservadores arguyen que la universalidad de los derechos humanos carece de significado porque los derechos, como la democracia, siempre son contingentes a la cultura y a la tradición: no son productos exportables. También argumentan que los derechos humanos son incompatibles con la soberanía: no es posible someter sus actos a

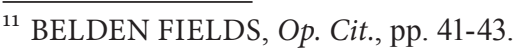

${ }^{12}$ Idem.
} 
tribunales extraños al país. Por su parte, los marxistas objetan que los derechos son sólo abstracciones vacías, una parte vital de la superestructura de la dominación capitalista. Para el Gobierno de los EUA los derechos políticos y civiles son indispensables, pero rechazan los derechos económicos, sociales y culturales, exceptuando el derecho a la propiedad privada de los individuos y las corporaciones. ${ }^{13}$

Visto en retrospectiva, parecería que en 1966 existía consenso en el mundo sobre los derechos humanos. Es cierto que en estos momentos prácticamente todos los países del mundo han firmado y ratificado uno o los dos pactos sobre estos derechos humanos y sus protocolos facultattivos. No obstante, aún hay desacuerdo con respecto a su contenido. Por ejemplo, en los años sesenta era común pensar que la lista de derechos debería ser lo más corta posible e incluso confinada sólo a los derechos políticos y civiles debido a que los derechos económicos, sociales y culturales no podían ser fácilmente traducidos al lenguaje legal, además de ser sólo aplicables a ciertos segmentos de la humanidad, perdiendo así la característica de universalidad que los derechos humanos deben tener. Aún hoy día algunos pensadores ${ }^{14}$ están convencidos que la lista de derechos humanos debe ser razonablemente corta y razonablemente abstracta.

A partir de esa diferenciación, los estudiosos de los derechos humanos vieron diferencias que en realidad carecen de fundamentos filosóficos y jurídicos. El hecho es que en 1948 sólo se hablaba de derechos humanos en general. No existían propiamente clasificaciones en la materia. Fue a partir de un conocido ensayo de Theodore H. Marshall, escrito en $1950,{ }^{15}$ que se empezó a hablar de derechos civiles, derechos políticos y derechos sociales como tres distintos momentos históricos que habrían conformado el núcleo actual de los sistemas de derechos.

Posteriormente, la percepción de diferencia entre tipos de derechos humanos se acrecentó a partir de la publicación de Pour une Troisième Génération des Droits de l'Homme, de Karel Vasak. ${ }^{16}$ Ahora es común en los círculos del derecho internacional referirse a "tres generaciones" de derechos que se articulan sobre estos documentos. Afirman que la primera generación la constituyen los derechos civiles y políticos que se desarrollaron a partir de los documentos del siglo XVIII. Son aparentemente sencillos de garantizar dado que sólo exigen abstenciones por parte de las autoridades. Para esta clasificación la segunda generación está compuesta por los derechos económicos, sociales y culturales. Los derechos económicos y sociales van más allá de la propiedad e incluyen derechos, en relación con necesidades, como el derecho al trabajo con paga justa, a una manera decorosa de vivir, a la seguridad social, a una distribución equitativa de alimentos. Estos derechos, dicen quienes sustentan que hay diferencias entre derechos de diversa generación, son sólo proclamas y buenos deseos,

\footnotetext{
13 Ibidem, p. 44.

14 Ver, por ejemplo, LUKES, Steven. "Five Fables About Human Rights", en Shute, Stephen y Hurley, Susan (eds.), On Human Rights. The Oxford Amnesty Lectures, New York, Basic Books, 1993, p. 38; o CRANSTON, Maurice. "Human Rights, Real and Supposed", en Winston, Morton E. (ed.). The Philosohy of Human Rights, Belmont, CA, Wadsworth, 1989, p. 126.

15 MARSHALL, Thomas Humphrey, "Ciudadanía y clase social”, publicado en Revista Española de investigaciones sociológicas, número 79, 1997, pp. 297-344, visible en http://www.reis.cis.es/REISWeb/PDF/ REIS_079_13.pdf.

${ }^{16}$ VASAK, Karel, Pour les droits de l'homme de la troisième génération, Strasbourg, Institut International des Droits de l'Homme, 1979. Idem, "Pour une troisième génération des droits de l'homme"; en Études et essais sur le droit international humanitaire et sur les principes de la Croix-Rouge en l'honneur de Jean Pictet, La Haye, Mouton, 1984. En español se publicó bajo el siguiente volumen: Vassak, Karel (ed.). Las dimensiones internacionales de los derechos humanos, España, Ed. Serbal/UNESCO, 1984.
} 
subordinados a la coyuntura económica y a las previsiones presupuestales que los poderes públicos pudieran realizar en ciertos periodos de tiempo. No obstante, se empezaron a consolidar a partir de la adopción del Pacto Internacional de Derechos Económicos, Sociales y Culturales de 1966 (PIDESC) por la Asamblea General de la Organización de Naciones las Unidas. ${ }^{17}$ De los derechos mencionados los culturales, no obstante, carecen del nivel de especificación que tienen los derechos económicos y sociales. Los de mayor grado de especificidad son el derecho a la educación y el de "participar en la vida cultural". ${ }^{18}$

La tercera generación, de reciente conceptualización, se refiere a los que Vasak llamó derechos de solidaridad. Enumeró esos derechos como los derechos al desarrollo, a la paz, al medio ambiente, a la comunicación y al patrimonio común que la humanidad comparte (e.g. los océanos). Existen ya dos declaraciones de la Organización de las Naciones Unidas que caerían en esta categoría: la Declaración sobre el Derecho de los Pueblos a la Paz ${ }^{19}$ de 1984 y la Declaración sobre el Derecho al Desarrollo ${ }^{20}$ de $1986 .{ }^{21}$ Para Vasak, la característica esencial de esos derechos es que sólo pueden ser realizados por todos los actores involucrados: el individuo, el Estado, las entidades públicas y privadas y la comunidad internacional. Su realización presupone que hay un mínimo de consenso social a niveles nacional e internacional para actos de solidaridad, sobre el reconocimiento de que tenemos responsabilidad solidaria. ${ }^{22}$

Hoy día se tiende ya el entramado para una cuarta, quinta y sexta generaciones de los derechos humanos. Los de la cuarta generación tienen que ver, en general, con el uso y aprovechamiento de las tecnologías de información y comunicación (TIC’s) como indispensables para satisfacer las necesidades de los individuos, de las comunidades y de la sociedad en general, así como la participación democrática, la diversidad lingüística y la identidad cultural, procurando iguales oportunidades en el acceso a las TIC's.

La quinta generación de derechos humanos, aunque suene raro, no es propiamente para seres humanos, sino para maquinas, artefactos, robots y software inteligente, para el día en que un robot pueda tener una conducta autárquica (libre) con respecto a su programador y realice un acto ilegal. ¿Habrá que castigarle? ¿Será necesario otorgarle derechos de protección legal justa? ${ }^{23}$

Y una sexta generación de derechos humanos, que sí sería aplicable a seres humanos, o lo que resulte de seres en un estado post-humano o, aún más extraño si es posible, personas

${ }^{17}$ ORGANIZACIÓN DE LAS NACIONES UNIDAS, Pacto Internacional de Derechos Económicos, Sociales y Culturales, A/RES/220o A (XXI), de 16 de diciembre de 1966. Visible en http://www.cinu.org.mx/onu/documentos/ pidesc.htm.

${ }^{18}$ Ibidem, ver artículo 15 , inciso a).

19 ORGANIZACIÓN DE LAS NACIONES UNIDAS, Declaración sobre el Derecho de los Pueblos a la Paz, Adoptada por la Asamblea General en su resolución 39/11, de 12 de noviembre de 1984, visible en http:// www2.ohchr.org/spanish/law/paz.htm.

${ }^{20}$ ORGANIZACIÓN DE LAS NACIONES UNIDAS, Declaración sobre el Derecho al Desarrollo, Adoptada por la Asamblea General en su resolución 41/128, de 4 de diciembre de 1986, visible en http://www2.ohchr.org/ spanish/law/desarrollo.htm.

${ }^{21}$ Hay un muy buen análisis de ambas declaraciones en BECERRA, Manuel R. "El derecho a la paz y el derecho internacional del desarrollo", en UNAM, Congreso Internacional sobre la Paz, Tomo I, México, UNAM, 1987, pp. 3-15, visible en $h t t p: / / w w w$. bibliojuridica.org/libros/1/258/3.pdf.

${ }^{22}$ Citado por Belden Fields, op. cit., p. 41.

${ }^{23}$ En mayo de 2014 la firma japonesa Deep Knowledge Ventures "nombró" una máquina de inteligencia artificial (IA) como miembro en su Junta Directiva. Se generaron muchas notas periodísticas la respecto. Ver por ejemplo, Zolfagharifard, Ellie. "Would you take orders from a ROBOT? An artificial intelligence be- 
que tengan una identidad genética-cognitiva-informacional alterada por una modificación nano-robo-tecnológica. Pero eso lo dejamos al futuro. Hoy aún nos ocupa nuestra lacerante realidad de no poder hacer plenamente exigibles los derechos económicos, sociales y culturales.

\section{LA INFLUENCIA DE LAS CLASIFICACIONES EN LA EXIGIBILIDAD DE LOS DERECHOS ECONÓMICOS, SOCIALES Y CULTURALES}

Plantearse una discusión sobre la exigibilidad de los derechos económicos, sociales y culturales lleva implícito asumir una clasificación de esos derechos. Las clasificaciones más comunes son la impuesta por los pactos internacionales, que divide los derechos humanos al menos en derechos civiles y políticos y en derechos económicos, sociales y culturales; la del discurso de las generaciones de derechos; la de derechos absolutos y relativos; la que clasifica los derechos en universales y particulares; la del discurso de los derechos inalienables y alienables, y aún se puedan añadir otros tipos de clasificaciones, como las de los "derechos de los pueblos", los “derechos al desarrollo", los “derechos ecológicos”, etcétera.

Estas clasificaciones, en realidad, son más o menos arbitrarias. Aunque compartan ciertos rasgos, no son consecuentes con ellos, ni corresponden propiamente a criterios estructurales, ni a criterios de justificación, aunque se pretenda afirmar diferencias estructurales o de justificación para cada categoría de derechos.

Desde el punto de vista histórico, estas clasificaciones también inducen a distorsiones porque nos presentan la historia por la lucha de los derechos como un especie de evolución que va, primero, de la conquista de los derechos civiles a los políticos, luego a los sociales y, finalmente, los que les sigan a éstos.

Estas clasificaciones han moldeado durante años nuestro pensamiento y concepción de los derechos. Cuando nos planteamos algunos asuntos, como la cuestión de la exigibilidad de los derechos sociales y culturales, nos vemos compelidos a dar explicaciones y justificaciones de por qué no se pueden exigir o garantizar adecuadamente estos derechos, a diferencia los derechos civiles y políticos, para los que asume que son más fáciles de proteger y garantizar.

Sostengo la idea, que ya han externado otros pensadores, de que en realidad no existe ninguna razón de fondo que impida pensar los derechos humanos, llámense civiles, políticos y sociales, como una categoría unitaria en aspectos importantes, aunque difieran en aspectos secundarios. Esto es así porque algunos de los llamados derechos civiles y políticos, desde un punto de vista estructural, comparten más rasgos con derechos sociales que con otros derechos civiles y políticos.

Si se acepta la necesidad de revisar las clasificaciones de derechos bajo las premisas antes descritas sería necesario rechazar algunas teorías constitucionales clásicas, como la que sostiene que la Constitución establece límites de carácter eminentemente negativo consistente en prohibiciones que delimitan la esfera protegida de cada persona, generado por un equilibrio entre los derechos de libertad individuales y los límites del poder estatal.

Empezamos con la clasificación, ya clásica, que indica que los derechos civiles y políticos requieren únicamente de abstenciones (acciones negativas) en tanto que los derechos económicos, sociales y culturales necesitan de obligaciones de dar o de hacer (acciones positivas).

comes the world's first company director", en Daily Mail, UK. Disponible en http://www.dailymail.co.uk/ sciencetech/article-2632920/Would-orders-ROBOT-Artificial-intelligence-world-s-company-director-Japan. html\#ixzz3MePJL5fl. 
Si revisamos el listado de derechos humanos constataremos fácilmente que esta clasificación no resiste ni el primer embate de análisis. Así, encontramos derechos generalmente considerados como sociales que requieren de abstenciones, como el derecho a huelga. Otros derechos sociales requieren de acciones positivas pero no requieren de recursos económicos, como los que restringen la autonomía individual en los contratos de trabajo, la limitación de la jornada laboral, el salario mínimo, las vacaciones anuales. En contrapartida, en los derechos civiles y políticos encontramos que existen también obligaciones de dar y de hacer, como el derecho a un juicio justo o el derecho a la integridad o seguridad personales o el ejercicio de los derechos políticos, que implican la creación y sostenimiento de instituciones, así como una partida de gastos directamente en el presupuesto estatal.

Otra clasificación habla de derechos absolutos y relativos. La idea de que un derecho fundamental sea absoluto es de cuño iusnaturalista. Es una idea que puede resultar un tanto absurda y contraria a nuestras percepciones. La idea presume que hay un sólo derecho absoluto y una jerarquía bien definida entre los derechos; o bien, cosa más difícil de conciliar con nuestras intuiciones, que los derechos absolutos, si son más de uno, no entran en conflicto entre sí. Para esta concepción un derecho no puede estar limitado, pero cambia cuando distinguimos entre "limitar" un derecho y "delimitarlo" en el sentido de restringirlo o sujetarlo a excepciones. ${ }^{24} \mathrm{El}$ derecho vale hasta donde comienza el derecho con el que limita, pero en ese momento deja de existir como derecho. Si en cambio adoptamos la perspectiva clásica, la de los derechos relativos, muy pocos derechos serían absolutos, pues es difícil no aceptar que la gran mayoría tiene excepciones. La tesis que acepta derechos humanos limitados por las disposiciones del órgano legislativo ordinario o reformador de la Constitución, conjetura no una lógica de convivencia, preservación o desarrollo social, sino revela un ámbito de penumbra cuya claridad resulta difícil de lograr en defensa del ser humano, que deviene en un poco o nula efectividad y protección en la práctica.

Para Ronald Dworkin, por ejemplo, un derecho es absoluto si resiste el embate de intereses colectivos o de decisiones mayoritarias. ${ }^{25}$ No cabe negar cualquier libertad, o cualquier derecho básico procesal sólo por afectar algún interés colectivo o porque así lo haya decidido la mayoría. Dworkin afirma que, cuando un derecho resiste justificadamente este tipo de consideraciones, estamos ante un derecho absoluto. Pero esta es una manera muy creativa y diferente de concebir el carácter absoluto de los derechos, porque aquí no se rechaza que estos derechos entren en conflicto con otros derechos fundamentales y frente a ellos queden delimitados.

Los derechos fundamentales son derechos prima facie que pueden ser derrotados por otros derechos o por consideraciones que apelen a situaciones de emergencia. Los derechos relativos serían aquellos que tienen que ceder ante otros derechos, o incluso ante consideraciones políticas o económicas.

Bajo los supuestos anteriores, en realidad no hay diferencia entre derechos civiles y políticos y los derechos sociales, de los cuales se suele decir que no son absolutos porque la mayoría de los primeros aceptan excepciones, es decir, admiten delimitaciones justificadas por la interacción con otros derechos.

A la afirmación de que los derechos sociales no pueden ser absolutos porque la disponibilidad de los recursos materiales los limita o condiciona, o porque su limitación derivada de

\footnotetext{
${ }^{24}$ MARTÍNEZ PUJALTE, Antonio, La garantía del contenido esencial de los derechos fundamentales, Madrid, Centro de Estudios Constitucionales, 1997, p. 19.

${ }^{25}$ DWORKIN, Ronald, Los derechos en serio. México, Planeta-Agostini, 1993, p. 160.
} 
argumentaciones políticas, se podría responder, primero, diciendo que ningún derecho (ni los civiles, ni los políticos ni los sociales) puede ser garantizado de manera absoluta frente a eventuales violaciones de funcionarios públicos o de particulares. El grado de ineficacia de la protección de un derecho no significa que no exista el derecho que merece tal protección. ${ }^{26}$ Segundo, la condición de la disponibilidad de recursos materiales para garantizarlos no es exclusiva de los derechos sociales. La concepción de que derechos civiles y políticos son gratuitos es totalmente falsa. Ningún derecho es gratis y muy pocos son baratos. ${ }^{27}$ Es cierto que proteger de algunas libertades puede resultar más barato que la de los derechos sociales, pero esto no significa que no cuesten. Los costos de algunos derechos civiles y políticos a veces no se aprecian porque se dan por asumidos y nadie los discute. En materia de derechos sociales, la discusión sobre la manera y cuantía del gasto o la inversión está influenciada por los intereses y la ideología.

En otra clasificación, encontramos que la doctrina distingue entre derechos universales y particulares. La universalidad es un rasgo que generalmente se le atribuye a los derechos civiles y políticos y que a veces se le niega a los sociales. Antes de negarla a estos últimos o de otorgarla a los primeros, primero habría que ponernos de acuerdo sobre lo que entendemos por universalidad. Para algunos autores, como Ferrajoli, por ejemplo, que los derechos sean universales significa que se trata de un predicado lógico-formal del tipo 'para todo $\mathrm{X}, \mathrm{X}$ tiene derecho a..... ${ }^{28}$ Esta postura ha sido criticada porque de ella se podrían derivar asertos que establecieran, por ejemplo: "para todo X, si X es profesor de filosofía del derecho de la Uni-

\footnotetext{
${ }^{26}$ A este respecto, la Segunda Sala de la Suprema Corte de Justicia de la Nación se ha pronunciado de manera muy interesante en la siguiente tesis: DERECHOS ECONÓMICOS, SOCIALES Y CULTURALES. CUANDO EL ESTADO ADUCE QUE EXISTE UNA CARENCIA PRESUPUESTARIA PARA SU REALIZACIÓN, DEBE ACREDITARLO. El contenido normativo del Pacto Internacional de Derechos Económicos, Sociales y Culturales, permite concluir que la obligación estatal de proteger, respetar y promover los derechos contenidos en ese instrumento no puede desconocer la situación particular que enfrente cada país, por lo que no existirá una violación a los derechos en él tutelados, a pesar de que se acredite que un determinado derecho no ha sido realizado o alcanzado un nivel óptimo de eficacia, siempre y cuando el Estado haya demostrado que ha utilizado todos los recursos que están a su disposición en un esfuerzo por satisfacer las obligaciones establecidas en la propia convención. De ahí que no basta la simple afirmación del Estado Mexicano de que existe limitación presupuestaria para que se tenga por acreditado que ha adoptado todas las medidas "hasta el máximo de los recursos" de que disponga, para lograr la realización de los derechos consagrados en el referido Pacto, sino que para ello deberá aportar el material probatorio en que sustente su dicho. Por tal motivo, en todo asunto en el que se impugne la violación a los derechos constitucionales de la materia, los juzga dores nacionales deben distinguir entre la incapacidad real para cumplir con las obligaciones que el Estado ha contraído en materia de derechos humanos, frente a la renuencia a cumplirlas, pues es esa situación la que permitirá determinar las acciones u omisiones que constituyan una violación a tales derechos humanos.

Amparo en revisión 378/2014. Adrián Hernández Alanís y otros. 15 de octubre de 2014. Mayoría de tres votos de los Ministros Alberto Pérez Dayán, José Fernando Franco González Salas y Luis María Aguilar Morales. Ausente: Sergio A. Valls Hernández. Disidente: Margarita Beatriz Luna Ramos. Ponente: Alberto Pérez Dayán. Secretaria:Georgina Laso de la Vega Romero.

SCJN. 2a. CIX/2014 (10a.), publicada en la Gaceta del Semanario del Semanario Judicial de la Federación, Libro 12, Tomo I, Noviembre de 2014, Pleno y Salas. México, SCJN, 2014, pp. 1190 y 1191.

${ }^{27}$ HOLMES, Stephen y SUSTEIN, Cass R., El costo de los derechos. Por qué la libertad depende de lo impuestos. Buenos Aires, Siglo XXI Editores, 2012.

${ }^{28}$ FERRAJOLI, Luigi, "Derechos fundamentales", en Ferrajoli, Luigi (comp.), Los fundamentos de los derechos fundamentales, $3^{\mathrm{a}}$ ed., edición de Cabo, Antonio de y Pisarello, Gerardo. Madrid, Trotta, 2007, p. 19.
} 
versidad de Camerino, entonces X es titular del derecho a G”, donde tal derecho a G quedaría conferido, en este caso, a una sola persona (a Luigi Ferrajoli). ${ }^{29}$

Otra concepción de universalidad adscribe derechos a todos los seres humanos, con independencia de las circunstancias y el contexto. Lo anterior nos lleva a tratar de entender la "universalidad" como el resultado de razones morales de tal fuerza que valdrían para todos los seres humanos. ${ }^{30}$ Aquí carece de importancia cómo se haya redactado el enunciado normativo en que se expresa un derecho humano; lo verdaderamente importante es que tenga la fuerza moral necesaria para extenderlo a todos los seres humanos.

Lo cierto es que, independientemente del significado de "universalidad" que nos guste, no es útil para distinguir entre derechos civiles, políticos y sociales, o entre derechos clasificados en generaciones, porque algunos de los derechos civiles y políticos no cumplirían el requisito de universalidad, en cualquiera de los sentidos, y a su vez, ciertos derechos sociales sí lo cumplirían, porque se pueden predicar para "todos los seres humanos".

Otra manera en que se trata de distinguir entre los derechos, es clasificándoles en derechos inalienables y alienables. Entendemos la inalienabilidad de los derechos como la imposibilidad moral de renunciar a ellos. En este sentido, la tradición clásica sostenía, por ejemplo, que uno no puede renunciar a su propia vida o a su propia libertad, pero sí podría renunciar a un seguro social, a una vivienda, etcétera. No son posibles los contratos de esclavitud, aunque ahora está en discusión la posibilidad de realizar el llamado testamento vital por el cual se autoriza la eutanasia.

Esta característica de inalienabilidad presenta algunos problemas, porque en principio habría que distinguir entre la idea de ser titular de un derecho y la capacidad para ejercerlo. Al aplicar la idea de inalienabilidad a esta distinción, entonces lo que es inalienable es la titularidad del derecho, aunque se pueda renunciar a su ejercicio. Pero con los derechos sociales ocurre algo semejante: puedo renunciar al ejercicio del derecho, pero no puedo renunciar al derecho en sí. Ahora bien: pueden existir también derechos humanos que, por su conexión con la dignidad de la persona o para garantizar el equilibrio en situaciones de poder desigual, no son sólo irrenunciables en su título, sino también en su ejercicio, es decir, su ejercicio es obligatorio. Pero aquí, también podemos encontrar derechos sociales cuyo ejercicio sea irrenunciable. Un ejemplo en el caso de derechos civiles y políticos sería el derecho a no ser torturado o el derecho a ser asistido por un abogado en los juicios penales o a un juicio justo; en el caso de los derechos sociales podemos tener el derecho a la enseñanza básica o el derecho a un medio ambiente sano.

Lo expuesto hasta aquí, nos nuestra que los criterios más comunes que intentan trazar la distinción entre los derechos civiles y políticos con los sociales no alcanzan realmente su objetivo.

Ahora bien, existe una manera diferente de aproximación a un sistema de clasificación más funcional: considerar que todos los derechos humanos son derechos, por decirlo de

\footnotetext{
${ }^{29}$ GUASTINI, Riccardo. “Tres problemas para Luigi Ferrajoli”, en Ferrajoli, Luigi (comp.), Los fundamentos de los derechos fundamentales, $3^{\mathrm{a}}$ ed., edición de Cabo, Antonio de y Pisarello, Gerardo. Madrid, Trotta, 2007, p. 60.

${ }^{30}$ Esta tesis es sostenida por Laporta, Francisco en "Sobre el concepto de derechos humanos", Doxa, Cuadernos de Filosofía del Derecho [Publicaciones periódicas] No. 4, 1987, disponible en http://www.cervantesvirtual.com/servlet/SirveObras/12837218659036051876657/index.htm. Juan Antonio Cruz Parcero critica esta concepción de universalidad en "Derechos morales: concepto y relevancia", en lsonomía: Revista de Teoría y Filosofía del Derecho, No. 15, octubre 2001. Disponible en http://bib.cervantesvirtual.com/servlet/SirveObras/12715196462382624198846/isonomia15/isonomia15_o2.pdf.
} 
alguna manera, prestacionales. El carácter negativo o positivo de las acciones no logra por sí mismo trazar diferencia en los derechos humanos, pero nos permitirá entender algunas cualidades de los derechos, sobre todo si regresamos nuevamente al carácter prestacional que se atribuyen en principio a todos los derechos sociales. Aquí sigo el pensamiento de Robert Alexy, quien ha propuesto una clasificación de los derechos que nos hace ver la dimensión prestacional de ciertos derechos considerados como civiles y políticos que suelen verse como totalmente ajenos a los derechos sociales. El profesor alemán atiende a la dimensión estructural de los derechos, lo que nos ayuda a reconocer aspectos de los mismos que quedan oscurecidos por las clasificaciones tradicionales. ${ }^{31}$

\section{LA DIMENSIÓN “PRESTACIONAL” DE TODOS LOS DERECHOS}

Alexy parte de una concepción de derecho prestacional en sentido amplio, donde la escala de las acciones positivas por parte del Estado pueden ser objeto de un derecho subjetivo que distingue "desde la protección del ciudadano frente a otros ciudadanos a través de normas del derecho penal, pasando por el dictado de normas de organización y procedimiento, hasta prestaciones en dinero y en bienes" ${ }^{32}$

La importancia de este distingo, que entraña una ampliación del concepto tradicional del derecho prestacional, es por doble razón. Primero, muchos de los derechos prestacionales contienen posiciones que apuntan en parte a prestaciones fácticas y en parte a prestaciones normativas, en los que se incluirían, por ejemplo, un derecho a que el Estado omita determinadas intervenciones, un derecho a que el Estado proteja al titular del derecho fundamental frente a intervenciones de terceros que impidan el goce del derecho, un derecho a que el Estado permita participar al titular del derecho en procedimientos relevantes en materia de asignación del derecho al procedimiento y un derecho a que el propio Estado realice medidas fácticas tendientes a mejorar el propio derecho (derecho a una prestación fáctica). La razón consiste, entonces, en que no todas las prestaciones que se relacionan con los derechos son prestaciones de dar o proporcionar servicios o recursos.

La segunda razón es que los derechos a acciones positivas (en sentido amplio) comparten problemas que no presentan, en absoluto, los derechos a acciones negativas. Los derechos a acciones negativas (derechos de defensa) imponen límites al Estado en la persecución de sus fines. No dicen nada acerca de los fines que tiene que perseguir el Estado. Los derechos a acciones positivas imponen al Estado la persecución de determinados objetivos. Debido a esto, todos los derechos a acciones positivas plantean al Estado el problema de saber si y en qué medida se puede y se debe imponer la persecución de fines del Estado a través de los derechos subjetivos constitucionales de los ciudadanos. Cuando una constitución somete los derechos constitucionales al control amplio de un tribunal constitucional, el problema es esencialmente de distribución de competencias entre el tribunal constitucional y el legislador. La participación de todos los derechos a acciones positivas del Estado en este problema es una razón decisiva para resumirlos en un grupo bajo la expresión general de "derechos a prestaciones". Los derechos a prestaciones fácticas, es decir, a prestaciones que también podrían proporcionar los particulares, constituyen sólo un sector de los derechos a presta-

\footnotetext{
${ }^{31}$ ALEXY, Robert, Teoría de los derechos fundamentales, $2^{\text {a }}$ ed., trad. y estudio introd. de C. BERNAL PULIDO, Madrid, Centro de Estudios Constitucionales, 2008.

${ }^{32}$ Ibidem, p. 427. 
ciones. Por esta razón, Alexy distingue, y sólo cuando le parece relevante, entre "derechos a prestaciones en sentido estricto" y "derechos a prestaciones en sentido amplio".

Para el autor alemán los derechos a prestaciones se pueden organizar en tres grupos: (a) derechos a protección; (b) derechos a organización y procedimiento; y (c) derechos a prestaciones en sentido estricto. Los derechos del tipo indicado son derechos fundamentales a prestaciones sólo si se trata de derechos subjetivos y constitucionales. Así, tienen que ser distinguidos de los derechos subjetivos que encontramos en normas de carácter secundario (no constitucionales) y de las normas que no confieren derechos subjetivos en este sentido (derechos objetivos). Los derechos subjetivos no constitucionales pueden ser derechos subjetivos otorgados por el derecho subconstitucional ${ }^{33}$ o derechos morales. Las normas que no confieren ningún derecho subjetivo pueden ser normas constitucionales o bien de normas del derecho ordinario o de normas morales. ${ }^{34}$

\section{(A) DERECHOS A PROTECCIÓN}

Los derechos a protección son los derechos frente al Estado que protejen al titular de estos derechos de intervenciones de terceros. Los derechos a protección pueden tener como objeto cosas muy diferentes, mediante no menos variadas formas de protección. El Estado tiene entonces que realizar una serie de acciones (físicas o normativas) con objeto de delimitar la esfera de los sujetos, es decir, la esfera donde los demás no pueden intervenir. Los derechos a protección se distinguen de los derechos de defensa en que los primeros son derechos a que el Estado omita intervenciones; los segundos, derechos frente al Estado para que éste asegure o persuada a terceros de no realizar ciertas acciones. Los derechos de defensa son para los destinatarios prohibiciones de destruir, de afectar negativamente, etcétera. Los derechos a protección son para los destinatarios mandatos de proteger o promover algo.

Los derechos de defensa son generales: si está prohibido destruir o afectar algo, entonces está prohibida toda acción que constituya o provoque una destrucción o afectación. Cuando está ordenado proteger o promover algo, cabe cualquier acción que constituya o provoque una protección o una promoción. Basta la realización de alguna de esas acciones que resulte efectiva; es decir, el obligado puede tener a su disposición diversas acciones dentro de las cuales puede elegir cómo desea cumplir el mandato. Sólo cuando exista una única acción adecuada de protección o promoción, se aplicaría ésta para el cumplimiento del derecho a prestación.

\section{(B) DERECHOS A PROCEDIMIENTO O DERECHOS PROCEDIMENTALES}

Según Alexy, hay cuatro tipos de derechos a procedimiento o procedimentales: a) competencias de derecho privado, b) procedimientos judiciales y administrativos, c) organización, y d) formación de la voluntad estatal. Los primeros son derechos frente al Estado para que éste formule normas constitutivas para la acciones de derecho privado que creen, modifiquen o extingan posiciones jurídicas dentro de las instituciones del derecho privado. El argumento

\footnotetext{
${ }^{33}$ Por ejemplo, las leyes que reglamentan los preceptos constitucionales.

34 ALEXY, Op. Cit., nota al pie 25, pp. 430-431.
} 
$\neq$ principal para considerarlos un tipo de derechos a prestaciones es que numerosos derechos presuponen conceptualmente la existencia de instituciones jurídicas de derecho privado.

Los derechos a procedimientos judiciales y administrativos son esencialmente derechos a una protección jurídica efectiva. A los derechos y libertades les corresponden procedimientos para garantizar estos derechos, apegados a cierto tipo de procedimientos, juicios justos, imparciales, con ciertas garantías que son el medio de mantener la vigencia de los demás derechos.

Los derechos a organización, en sentido estricto, son derechos del individuo dirigidos al legislador para que emita ciertas normas de organización afines al contenido de los derecho humanos. Los derechos a la formación de la voluntad estatal son derechos de los individuos para que el legislador ordinario facilite los procedimientos que posibiliten la participación en la formación de la voluntad estatal. Estos derechos incluyen el derecho al voto y a ser elegidos para formar parte de los órganos de gobierno.

\section{(C) DERECHOS A PRESTACIONES EN SENTIDO ESTRICTO}

Alexy define los derechos a prestaciones en sentido estricto como derechos del individuo frente al Estado a algo que - si el individuo poseyera medios financieros suficientes y si encontrase en el mercado una oferta suficiente- podría obtenerlo también de particulares. ${ }^{35}$

Esta dimensión prestacional es la que prácticamente se asocia con los derechos sociales, como, por ejemplo, el derecho a la vivienda, la educación, servicios sociales, subsidios, etcétera. Resalta el carácter económico de los derechos, cuya satisfacción exige una transferencia de recursos de los sectores más ricos a los más pobres. Esto es lo que siempre ha generado fuertes reticencias cuando se les quiere garantizar jurídicamente. Se trata pues, de un problema de redistribución. ${ }^{36}$

\section{CONCLUSIÓN}

Concluyo este ensayo reiterando la necesidad de encontrar nuevas herramientas conceptuales que nos sirvan para pensar los derechos en general y, específicamente, los que hemos encasillado como derechos sociales, económicos y culturales, cuya comprensión teórica, derivada de la influencia de las clasificaciones, ha conducido a limitarlos indebidamente. No estoy diciendo que dejen de utilizarse las clasificaciones. Sólo digo que debemos tener cuidado de no perder objetividad cuando se utilizan los cristales que proporciona cada tipo de clasificación de derechos, porque a veces y sin querer, la mezcla de tipos o niveles de clasificaciones puede provocar la aceptación o el rechazo de las posibilidades reales de exigibilidad de ciertos derechos, en función de lo que encaje o no con la estructura que proporciona cada clasificación.

\footnotetext{
35 Ibidem, p. 482.

${ }^{36}$ Un análisis muy interesante al respecto aparece en CRUZ PARCERO, J. A. "Los derechos sociales como técnica de protección jurídica”, en CARBONELL, M., CRUZ PARCERO, J. A. y VÁZQUEZ, R. (comps.), Derechos sociales y derechos de las minorías, Porrúa-UNAM, 21ª ed., 2001, pp. 87-110.
} 
VI. FUENTES

BIBLIOGRÁFICAS

ALEXY, Robert, Teoría de los derechos fundamentales, $2^{\text {a }}$ ed., trad. y estudio introd. de C. BERNAL PULIDO, Madrid, Centro de Estudios Constitucionales, 2008.

BECERRA RAMÍREZ, Manuel, El factor jurídico en la transformación de la Unión Soviética a la Comunidad de Estados Independientes. México, UNAM, 1992. Visible en: http://www.bibliojuridica.org/ libros/2/827/11.pdf.

_- _ _ _ _ _ - "El derecho a la paz y el derecho internacional del desarrollo", en UNAM, Congreso Internacional sobre la Paz, Tomo I, México, UNAM, 1987. Visible en $h t t p: / / w w w . b i b l i o j u r i d i c a . o r g / l i b r o s / 1 / 258 / 3 . p d f$.

BELDEN FIELDS, A. Rethinking human rights for the new millennium, New York, Palgrave Macmillan, 2003.

CRANSTON, Maurice. "Human Rights, Real and Supposed", en Winston, Morton E. (ed.). The Philosohy of Human Rights, Belmont, CA, Wadsworth, 1989.

CRUZ PARCERO, Juan Antonio. "Derechos morales: concepto y relevancia”, en lsonomía: Revista de Teoría y Filosofía del Derecho, No. 15, octubre 2001. Disponible en http:// bib.cervantesvirtual.com/servlet/SirveObras/12715196462382624198846/isonomia15/ isonomia15_02.pdf.

,"Los derechos sociales como técnica de protección jurídica", en Carbonell, M., Cruz Parcero, J. A. y VÁZQUEZ, R. (comps.), Derechos sociales y derechos de las minorías, Porrúa-UNAM, 21 a ed., 2001, pp. 87-110.

DWORKIN, Ronald. Los derechos en serio. México, Planeta-Agostini, 1993.

FERRAJOLI, Luigi, "Derechos fundamentales”, en Ferrajoli, Luigi (comp.), Los fundamentos de los derechos fundamentales, $3^{\mathrm{a}}$ ed., edición de Cabo, Antonio de y Pisarello, Gerardo. Madrid, Trotta, 2007.

GUASTINI, Riccardo, Estudios de teoría constitucional, México, Fontamara-UNAM, 2001. Disponible también en Internet, http://biblio.juridicas.unam.mx/libros/libro. htm?l=22.

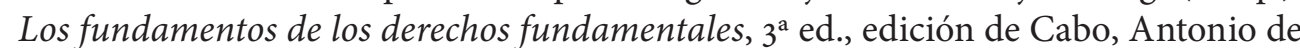
y Pisarello, Gerardo. Madrid, Trotta, 2007.

HOLMES, Stephen y SUSTEIN, Cass R. El costo de los derechos. Por qué la libertad depende de lo impuestos. Buenos Aires, Siglo XXI Editores, 2012.

ISHAY, Micheline R. The History of Human Rights. From Ancient Times to the Globalization Era, 2 a ed., Berkeley, University of California Press, 2008. 
LAPORTA, Francisco. "Sobre el concepto de derechos humanos", en Doxa, Cuadernos de Filosofía del Derecho, No. 4, 1987, disponible en http://www.cervantesvirtual.com/servlet/SirveObras/12837218659036051876657/index.htm.

LUKES, Steven, "Five Fables About Human Rights", en Shute, Stephen y Hurley, Susan (eds.), On Human Rights. The Oxford Amnesty Lectures, New York, Basic Books, 1993.

MARSHALL, Thomas Humphrey, "Ciudadanía y clase social”, publicado en Revista Española de investigaciones sociológicas, número 79, 1997. Visible en http://www.reis.cis. es/REISWeb/PDF/REIS_079_13.pdf.

MARTÍNEZ PUJALTE, Antonio, La garantía del contenido esencial de los derechos fundamentales, Madrid, Centro de Estudios Constitucionales, 1997.

NIETZSCHE, Friedrich, La genealogía de la moral. Visible en http://www.pensament.com/ filoxarxa/filoxarxa/pdf/Nietzsche,\%2oFriedrich\%20-\%2oGenealogia\%2ode\%2ola\%2o moral\%2o (completo). pdf.

OEHLING RUIZ, Hermann, La nueva Constitución Soviética de 7 de octubre de 1977. Visi-

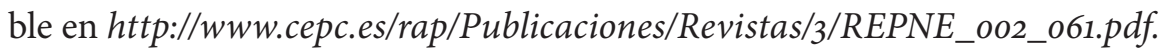

ORGANIZACIÓN DE LAS NACIONES UNIDAS, Declaración sobre el Derecho de los Pueblos a la Paz, Adoptada por la Asamblea General en su resolución 39/11, de 12 de noviembre de 1984, visible en http://www2.ohchr.org/spanish/law/paz.htm.

- - - - _ - _ - Declaración sobre el Derecho al Desarrollo, Adoptada por la Asamblea General en su resolución 41/128, de 4 de diciembre de 1986, visible en $h t t p: / /$ www2.ohchr.org/spanish/law/desarrollo.htm.

_- _ _ _ _ _ _ - Pacto Internacional de Derechos Económicos, Sociales y Culturales, A/RES/220o A (XXI), de 16 de diciembre de 1966. Visible en http://www.cinu.org. mx/onu/ documentos/ pidesc.htm.

SCJN. 2a. CIX/2014 (10a.), publicada en la Gaceta del Semanario del Semanario Judicial de la Federación, Libro 12, Tomo I, Noviembre de 2014, Pleno y Salas. México, SCJN, 2014, pp. 1190 y 1191, bajo el rubro: DERECHOS ECONÓMICOS, SOCIALES Y CULTURALES. CUANDO EL ESTADO ADUCE QUE EXISTE UNA CARENCIA PRESUPUESTARIA PARA SU REALIZACIÓN, DEBE ACREDITARLO.

TROTSKY, Leon, La revolución traicionada, visible en http://www.marxismo.org/ ?q=node $/ 157$.

Unión de Repúblicas Socialistas Soviéticas. Constitución Soviética de 1936. Visible en: http://www.eroj.org/biblio/stalin/ constiz6/constiz6.htm\#XIII.

VASAK, Karel, "Pour une troisième génération des droits de l'homme”; en Études et essais sur le droit international humanitaire et sur les principes de la Croix-Rouge en l'honneur de Jean Pictet, La Haye, Mouton, 1984.

Institut International des Droits de l'Homme, 1979. 
-, (ed.). Las dimensiones internacionales de los derechos humanos, España, Ed. Serbal/UNESCO, 1984.

ZOLFAGHARIFARD, Ellie, "Would you take orders from a ROBOT? An artificial intelligence becomes the world's first company director", en Daily Mail, UK. Disponible en http://www.dailymail.co.uk/sciencetech/article-2632920/Would-orders-ROBOT-Artificial-intelligence-world-s-company-director-Japan.html\#ixzz3MePJL5fl. 